Elsevier required licence: (c) <2019>. This manuscript version is made available under the CC-BY-NC-ND 4.0 license http://creativecommons.org/licenses/by-nc-nd/4.0/ The definitive publisher version is available online at https://doi.org/10.1016/j.watres.2019.05.011 


\title{
The treatability of trace organic pollutants in WWTP effluent and associated biotoxicity reduction by advanced treatment processes for effluent quality improvement
}

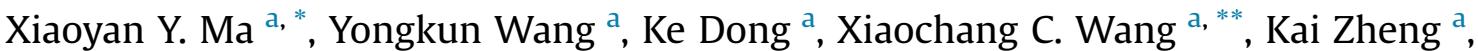 \\ Liwei Hao ${ }^{a}$, Huu Hao Ngo ${ }^{b}$
}

a International Science \& Technology Cooperation Center for Urban Alternative Water Resources Development, Key Lab of Northwest Water Resource, Environment and Ecology, MOE; Engineering Technology Research Center for Wastewater Treatment and Reuse, Shaanxi Key Laboratory of Environmental Engineering, Xi'an University of Architecture and Technology, Xi'an, 710055, Shaanxi Province, PR China

${ }^{\mathrm{b}}$ School of Civil and Environmental Engineering, Faculty of Engineering and Information Technology, University of Technology Sydney, Broadway, NSW, 2007, Australia

Keywords:

Treatability

Biotoxicity

Trace organic pollutants

Advanced treatment process

Effect-based trigger

\begin{abstract}
A B S T R A C T
As increasing attention is paid to surface water protection, there has been demand for improvements of domestic wastewater treatment plant (WWTP) effluent. This has led to the application of many different advanced treatment processes (ATPs). In this study, the treatability of trace organic pollutants in secondary effluent (SE) and associated biotoxicity reduction by four types of ATPs, including coagulation, granular activated carbon (GAC) adsorption, ultraviolet (UV) photolysis and photocatalysis, and ozonation, were investigated at the bench-scale. The ATPs showed different removal capacity for the 48 chemicals, which were classified into seven categories. EDCs, herbicides, bactericides and pharmaceuticals were readily degraded, and insecticides, flame retardants, and UV filters were relatively resistant to removal. During these processes, the efficiency of the ATPs in reducing four biological effects were investigated. Of the four biological effects, the estrogenic activity from SE was not detected using the yeast estrogen screen. In contrast with genotoxicity and photosynthesis inhibition, bacterial cytotoxicity posed by SE was the most difficult biological effect to reduce with these ATPs. GAC adsorption and ozonation were the most robust treatment processes for reducing the three detected biotoxicities. UV photolysis and photocatalysis showed comparable efficiencies for the reduction of genotoxicity and photosynthesis inhibition. However, coagulation only performed well in genotoxicity reduction. The effect-based trigger values for the four bioassays, that were derived from the existing environmental quality standards and from HC5 (hazardous concentration for $5 \%$ of aquatic organisms), were all used to select and optimize these ATPs for ecological safety. Conducting ATPs in more appropriate ways could eliminate the negative effects of WWTP effluent on receiving water bodies.
\end{abstract}

\section{Introduction}

The increasing occurrence of trace organic pollutants (TOPs; e.g. pharmaceuticals, bactericides, and flame retardants) and biological responses (e.g. photosynthesis inhibition, estrogenic activity, and carcinogenic effects) detected in wastewater, provides strong

\footnotetext{
* Corresponding author.

** Corresponding author.

E-mail addresses: maxiaoyan@xauat.edu.cn (X.Y. Ma), xcwang@xauat.edu.cn (X.C. Wang).
}

evidence of the adverse effects of secondary effluent (SE) on aquatic environments (Escher et al., 2014; Leusch et al., 2014; Pasquini et al., 2014; Link et al., 2017). With growing attention being focused on surface water pollution, there is an urgent need to improve the water quality of SE, which is one of the most significant sources of pollution to surface waters. In response to surface water pollution, the Chinese government plans to amend the Discharge Standard of Pollutants for Municipal Wastewater Treatment Plant (GB, 18918-2002) through appending special discharge indicator values. These values will be set according to level IV of the Environmental Quality Standard of Surface Water (GB 3838-2002; 


\begin{tabular}{|c|c|c|c|}
\hline \multirow{2}{*}{\multicolumn{2}{|c|}{ Abbreviations }} & EQS & environmental quality standards \\
\hline & & Fluoxetine & $\mathrm{HCl}$ fluoxetine hydrochloride \\
\hline ATPs & advanced treatment processes & FRs & flame retardants \\
\hline BEQ & bioanalytical equivalent concentration & GAC & activated carbon \\
\hline $\mathrm{BOD}_{5}$ & biochemical oxygen demand & $\mathrm{HC} 5$ & hazardous concentration for $5 \%$ of aquatic organisms \\
\hline BP1 & 2,4-dihydroxybenzophenone & 4-NQO & 4-nitroquinoline- $\mathrm{N}$-oxide \\
\hline BP3 & 2-hydroxyl-4-methoxyl benzophenone & OC & octocrilene \\
\hline BP4 & 2-hydroxyl-4-methoxyl benzophenone-sulfonic acid & OD-PABA & 2-ethylhexyl 4-dimethylaminobenzoat \\
\hline $\mathrm{BPA}$ & bisphenol A & $\mathrm{PACl}$ & poly-aluminum chloride \\
\hline CLP-m & chlorpyrifos-methyl & REF & relative enrichment factor \\
\hline COD & chemical organic demand & SE & secondary effluent \\
\hline DOC & dissolved organic carbon & SPE & solid phase extraction \\
\hline DMSO & dimethyl sulfoxide & SSDs & species sensitivity distributions \\
\hline DOM & dissolved organic matter & TBP & tributyl phosphate \\
\hline $\mathrm{DPH}-\mathrm{HCl}$ & diphenhydramine hydrochloride & $\mathrm{TiO}_{2}$ & titanium dioxide \\
\hline E1 & estrone & TOPs & trace organic pollutants \\
\hline E2 & $17 \beta$-estradiol & TPeP & triphenyl phosphate \\
\hline E3 & estriol & $\mathrm{TP}$ & total phosphorus \\
\hline EBT & effect-based trigger & ТРPO & triphenylphosphine oxide \\
\hline EC & effective concentration & WFD & Water Framework Directive \\
\hline EDCs & endocrine disruptors & WWTP & wastewater treatment plant \\
\hline EE2 & 17a-ethinylestradiol & YES & yeast estrogen screen \\
\hline EHMC & 2-ethyl-hexyl-4-trimethoxycinnamate & & \\
\hline
\end{tabular}

$\left.\mathrm{COD} \leq 30 \mathrm{mg} / \mathrm{L} ; \mathrm{BOD}_{5} \leq 6 \mathrm{mg} / \mathrm{L} ; \mathrm{NH}_{4}^{+}-\mathrm{N} \leq 1.5 \mathrm{mg} / \mathrm{L} ; \mathrm{TP} \leq 0.3 \mathrm{mg} / \mathrm{L}\right)$. To meet these improved standards, many advanced treatment processes (ATPs) have been applied or are being applied in municipal wastewater treatment plants (WWTPs) in China, such as those located in Beijing, Tianjin, and Wuxi (Wang et al., 2018a).

However, the wastewater treatment with only the aim of controlling general pollution parameters, such as $\mathrm{COD}$ and $\mathrm{BOD}_{5}$, cannot satisfy the increasing safety needs related to aquatic ecosystems (Macova et al., 2011; Gavrilescu et al., 2015; Tang et al., 2016). Thus, bioassays (effect-based assays) are required to provide vital supplementary information to chemical analyses to present a comprehensive overview of the adverse effects posed by SE. Bioassay results can reflect the combined biological effects of all active chemicals in a sample (Zhang et al., 2012). When individual chemicals are present below the limits of environmental standards, the biotoxicity of their mixture may still be significant (Silva et al., 2002). Numerous studies have employed bioassays to evaluate the efficiency of the treatment processes (Altmann et al., 2012; Wei et al., 2012; Jia et al., 2015; Freitas et al., 2016), but little is known about the selectivity of biotoxicity reduction by different ATPs.

The biotoxicity reduction efficiency of an ATP is related to the removal of individual TOPs, as well as operating parameters and properties of the treatment technology, etc. (Grandclément et al., 2017; Ogbeide et al., 2018; Wang et al., 2018b). In particular, the specific biological effects from tested sample are mainly caused by the responsible chemicals in the sample; for example, PSII photosynthesis inhibition effects correlate well with the herbicide content of the tested sample (Tang and Escher, 2014; Hashmi et al., 2018). Hence, it is essential to investigate the treatability of TOPs during ATPs, especially the chemicals responsible for the biological effects. However, numerous studies have only focused on the removal of TOPs or biotoxicity by ATPs in full-scale (Wang et al., 2018a,b). This could not investigate the influence of operating parameters used in ATPs on removal of TOPs and biotoxicity. Additionally, it is unclear that whether the TOPs and biotoxicity need to be decreased up to undetectable levels all the way. The finding of detectable biotoxicity for a sample does not necessarily mean that the level of response detected is unacceptable. Rather, the endpoint of the treatment process should be set based on the discharged wastewater which should not pose adverse aquatic ecological effects.

A defect that impedes the widespread application of bioassays is the lack of assessment methods to indicate which level of biological response is acceptable for ecological safety (Xu et al., 2014). Recently, studies have been engaged in the derivation of effectbased trigger (EBT) values to define the thresholds of bioassays. They are primarily derived from existing environmental quality standards (EQS) or from HC5 based on species sensitivity distributions (SSDs) (Tang et al., 2013; Escher et al., 2014; Jarošová et al., 2014; Oost et al., 2017; Daniels et al., 2018; Fournier et al., 2018). Hence, the development of EBT derivations provides an effective method to evaluate the biotoxicity reduction efficiency of ATPs and their acceptable endpoints from the perspective of aquatic ecological safety. Because the derivation of EQS-EBTs and HC5-EBTs are based on different concepts and require substantial toxicological data for many chemicals, no study has yet applied EQS-EBTs and HC5-EBTs simultaneously and compared their assessment results.

In the present study, four bioassays, including non-specific bacterial cytotoxicity, reactive genotoxicity, specific photosynthesis inhibition, and estrogenic activity, were applied to assess the treatability of TOPs by four types of ATPs. The biotoxicity reduction effectiveness of these ATPs was also evaluated using EQS-EBTs and HC5-EBTs, and strategies for biotoxicity control based on the optimization of ATPs were proposed to improve WWTP effluent quality and ecological safety.

\section{Materials and methods}

\subsection{Secondary effluent of WWTP}

Considering that the substances contained in SE, such as dissolved organic matter (DOM) and inorganic substances, could affect the efficiency of ATPs, the present study used authentic wastewater rather than artificial wastewater. Secondary effluent (SE) was collected before chlorination from a local WWTP in Xi'an, China, 
where anaerobic-anoxic-oxic biological treatment processes are applied. The treatment capability of the WWTP was $2 \times 10^{5} \mathrm{~m}^{3} / \mathrm{d}$. The water quality of the effluent was stable, and its traditional water quality parameters are shown in SI Table S1. The collected SE was fed into brown glass bottles that had been cleaned with potassium dichromate-concentrated sulfuric acid solution before collection, and was transported to the laboratory immediately. The collected SE was then subjected to advanced treatment within $24 \mathrm{~h}$.

\subsection{Advanced treatments}

The SE underwent four types of ATPs, including coagulation, granular activated carbon (GAC) adsorption, ultraviolet (UV) photolysis and photocatalysis, and ozonation in the laboratory. To investigate the relationship between the operating parameters of these ATPs (e.g., coagulant concentration and UV irradiation time) and toxicity reduction efficiency, bench-scale experiments were conducted. The SE collected in every batch $(30 \mathrm{~L})$ was treated with only one ATP, in which different parameters were set. The $\mathrm{UV}_{254}$ and DOC of wastewater after ATPs were detected, and their values are shown in SI Table S2.

For the coagulation treatment, a series of concentrations of polyaluminum chloride (PACl) $(0-400 \mathrm{mg} / \mathrm{L})$ was added to the $\mathrm{SE}$, followed by stirring in an electric mixer for $1 \mathrm{~min}$ at $200 \mathrm{rpm}$ for fast mixing, and for $30 \mathrm{~min}$ at $50 \mathrm{rpm}$ for slow mixing, and a settling period of up to $30 \mathrm{~min}$. In the GAC adsorption treatment, commercial shell GAC was used. Different concentrations of GAC $(0-30 \mathrm{~g} / \mathrm{L})$ were added to SE. They were stirred at $200 \mathrm{rpm}$ and allowed to settle up to $30 \mathrm{~min}$.

UV photolysis and photocatalysis experiments were performed in a batch reactor which was assembled from a cylindrical Pyrexglass cell (inner diameter: $18 \mathrm{~cm}$; height: $20 \mathrm{~cm}$ ) with a $5 \mathrm{~L}$ effective volume, a magnetic stirrer, and three $16 \mathrm{~W}$ immersed lowpressure mercury lamps placed at the center of the reactor. The irradiation source emitted light primarily at $254 \mathrm{~nm}$. Each reactor was placed in cooling equipment and maintained at $25 \pm 1^{\circ} \mathrm{C}$. UV photocatalysis experiments were set at either a low irradiance of $3.17 \mathrm{~mW} / \mathrm{cm}^{2}$ (termed "UV photocatalysis-low") or a high irradiance of $5.16 \mathrm{~mW} / \mathrm{cm}^{2}$ (termed "UV photocatalysis-high"). The fluence rate was measured using a UV-C irradiatometer at $254 \mathrm{~nm}$ (Beijing Normal University Photoelectric Instrument, China). The accumulated energy dose in the reactor for the treated wastewater was calculated based on the irradiance, irradiation time, and treated water volume (Ortega-Gómez et al., 2016). With $0-8 \mathrm{~h}$ of irradiation, the calculated accumulated energy doses of the two sets of treatments ranged from 0 to $10.32 \mathrm{~kJ} / \mathrm{L}$ and 0 to $16.47 \mathrm{~kJ} / \mathrm{L}$, respectively (SI Table S2). Before UV irradiation, $50 \mathrm{mg} / \mathrm{L}$ of commercially available Degussa P25-type titanium dioxide $\left(\mathrm{TiO}_{2}\right)$ was added to the wastewater samples, and they were then stirred in the dark for $2 \mathrm{~h}$ to reach an adsorption equilibrium between the catalyst surface and organic pollutants. The irradiation times were set between 0 and $8 \mathrm{~h}$.

The ozonation experiments were carried out at room temperature $\left(25 \pm 1{ }^{\circ} \mathrm{C}\right)$. Ozone-containing gas was continuously produced by an ozone generator (SanKang, Jinan, China) which was fed with pure oxygen. The ozone produced was pumped into the glass reactor (with an effective volume of $5 \mathrm{~L}$ ) and reacted with $3.5 \mathrm{~L}$ of SE. At the end of the reaction, high-purity nitrogen was fed into the reactor for $5 \mathrm{~min}$ to strip the remaining ozone in the reactor. All unreacted ozone in the off-gas was destroyed in two sequential $350 \mathrm{~mL} 2 \% \mathrm{KI}$ trap bottles in the terminal ozonation reactor. The concentrations of ozone in the in-gas and off-gas of the reactor were measured according to Kasprzyk-Hordern et al. (2006). The dissolved total organic carbon concentration of the treated wastewater was $7.93 \mathrm{mg} / \mathrm{L}$. With a reaction time of $0-30 \mathrm{~min}$, the reacted ozone dosage was in the range of $0-1.31 \mathrm{gO}_{3} / \mathrm{gDOC}(0-10.42 \mathrm{mg}$ $\left.\mathrm{O}_{3} / \mathrm{L}\right)$.

\subsection{Sample preparation for chemical analysis and bioassays}

The treated wastewater was collected and filtered through a $0.8 \mu \mathrm{m}$ glass microfiber filter $\left(\Phi=150 \mathrm{~mm}\right.$; Whatman $\left.{ }^{\mathrm{TM}}\right)$. Three liters of filtered water sample were prepared for solid phase extraction (SPE), according to the modified methods in our previously published study (Ma et al., 2016). Briefly, the prepared water samples were extracted with Waters Oasis HLB $(500 \mathrm{mg}, 6 \mathrm{~mL})$ cartridges which were preconditioned with $10 \mathrm{~mL}$ of a $1: 1 \mathrm{n}$-hexane-dichloromethane mixture, $10 \mathrm{~mL}$ of methanol, and $10 \mathrm{~mL}$ of milli-Q water, respectively. The cartridges were separately eluted with $10 \mathrm{~mL}$ of methanol and $10 \mathrm{~mL}$ of a $1: 1 \mathrm{n}$-hexane-dichloromethane mixture. The eluates were evaporated to dryness at a constant temperature of $40^{\circ} \mathrm{C}$ using a nitrogen evaporator (Sample Concentrator MD200, China), and then were redissolved in $1.5 \mathrm{~mL}$ of methanol. The residues were divided into triplicate samples for GC/MS analysis, LC/MS analysis, and bioassays (all $0.5 \mathrm{~mL}$ each). The solvent of the residuals was changed to acetone for GC/MS analysis $(1 \mathrm{~mL})$ and to $1 \%$ dimethyl sulfoxide (DMSO) $(1 \mathrm{~mL})$ for the bioassays. The volumes of samples prepared for LC/MS analysis were increased up to $1 \mathrm{~mL}$ using methanol due to instrumental needs.

\subsection{Chemical analysis}

To identify the TOPs in the SE, a full scan was carried out, and 48 chemicals were selected and classified in detail. These TOPs included 4 EDCs, 7 herbicides, 10 insecticides, 5 bactericides, 13 pharmaceuticals, 6 UV filters, and 3 flame retardants (FRs). Six analytical procedures were performed to quantitatively analyze the concentrations of the target chemicals in the water samples using a TSQ Quantum XLS (GC/MS, Thermo, USA) equipped with a DB-5MS $(30 \mathrm{~m} \times 0.25 \mathrm{~mm} \times 0.25 \mathrm{~m}$ ) capillary column and an ACQUITY UPLC - Xevo TQ MS (UPLC/MS, Waters, USA) equipped with an ACQUITY BEH C18 column $(100 \mathrm{~m} \times 2.1 \mathrm{~mm} \times 1.7 \mathrm{~m})$. The details of all these analytical procedures are presented in SI Table S3. The recovery of all 48 chemicals with individual concentrations of $5 \mu \mathrm{g} / \mathrm{L}$ and $50 \mu \mathrm{g} /$ L were $62.0-129.6 \%$ and $60.4-129 \%$, respectively, as shown in SI Table S4. In every batch of advanced treatments applied, samples of ultrapure water were set following the treatment and analysis procedures for quality assurance and quality control. The method limit of quantification (LOQ) was set at the laboratory LOQ which was ten times of $\mathrm{S} / \mathrm{N}$. The LOQs of the target chemicals are shown in SI Table S4.

\subsection{Bioassays}

Four bioassays, including a luminescent bacteria toxicity test, SOS/umu test, a combined algae test ( 2 h-PSII), and yeast estrogen screen (YES), were conducted to evaluate the biological responses of SE before and after ATPs, following our previous studies (Table 1). The species, quantitative indices, and reference compounds used in the bioassays are summarized in Table 1.

The dose metric of the water samples is defined as the relative enrichment factor (REF) of the water sample during SPE, which is calculated as the volume of the original water sample, $V_{\text {water sample, }}$ divided by the volume of its SPE extract, $V_{S P E}$ extract, and then multiplied by the dilution factor used in the bioassay (Equation (1)) (Macova et al., 2011).

$\mathrm{REF}=\frac{\mathrm{V}_{\text {water sample }}}{\mathrm{V}_{\mathrm{SPE} \text { extract }}} \times$ dilution factor $_{\text {bioassay }}$ 
Table 1

Bioassays and their quantitative indices used in the present study.

\begin{tabular}{|c|c|c|c|c|c|c|}
\hline Bioassays & Categories & Species & Reference compounds & Index & BEQ & Citation \\
\hline Luminescent bacteria toxicity test & Non-specific & Aliivibrio fischeri & Phenol & $\mathrm{EC}_{50}$ & $\mathrm{BEQ}_{\text {phenol }}$ & Ma et al. (2016) \\
\hline SOS/umu test & Reactive & Salmonella typhimurium TA1535/pSK1002 & 4-NQO & $\mathrm{IR}_{1.5}$ & $\mathrm{BEQ}_{4-\mathrm{NQO}}$ & Ma et al. (2016) \\
\hline Combined algae test ( 2 h-PSII) & Specific & Chlorella vulgaris & Diuron & $\mathrm{EC}_{50}$ & $\mathrm{BEQ}_{\text {diuron }}$ & Zheng et al. (2019) \\
\hline YES assay & Specific & Saccharomyces cerevisae & E2 & $\mathrm{EC}_{10}$ & $\mathrm{BEQ}_{\mathrm{E} 2}$ & Zhang et al. (2017) \\
\hline
\end{tabular}

The effect concentration (EC) of each bioassay for the detected sample was derived from REF - effect curves. It was expressed as the $\mathrm{EC}_{50}$ for luminescent bacteria toxicity test and photosynthesis inhibition test, the $\mathrm{IR}_{1.5}$ for the SOS/umu test, and the $\mathrm{EC}_{10}$ for YES. To make the biological responses comparable, the biotoxicity of the water sample was standardized to the bioanalytical equivalent concentration (BEQ), as shown in Table 1. The BEQ was calculated as the $\mathrm{EC}_{10}, \mathrm{EC}_{50}$ or $\mathrm{IR}_{1.5}$ of the reference compound divided by the $\mathrm{EC}_{10}, \mathrm{EC}_{50}$ or $\mathrm{IR}_{1.5}$ of the water sample (Equation (2)) (Stalter et al., 2016).

$\mathrm{BEQ}=\frac{\mathrm{EC}_{10}, \mathrm{EC}_{50} \text { or } \mathrm{IR}_{1.5} \text { of reference compound }}{\mathrm{EC}_{10}, \mathrm{EC}_{50} \text { or } \mathrm{IR}_{1.5} \text { of water sample }}$

By using BEQ, the effect of the water sample was characterized as the concentration of a reference compound that would drive the same effect as all of the compounds in the water sample. This permitted to calculate the toxicity reduction efficiency in one ATP.

\subsection{Effect-based trigger value derivation}

The EBT values for the selected bioassays were derived from the existing EQS and from HC5. Escher et al. (2015, 2018) and Oost et al. (2017) developed different methods to derive EQS-EBTs. The EQSEBTs of the four bioassays, including luminescent bacteria toxicity test, SOS/umu test, combined algae test and YES, were collected from published studies as shown in SI Table S5. Because the EC of a reference compound used in the bioassay has strong influence on the derivation of its EQS-EBT. Hence, the ratio of the EC determined in the present study to that from the published literature was used to amend the EQS-EBT, and the applied EQS-EBTs were presented in SI Table S5. More details for deriving EQS-EBTs are provided in SI Section $\mathrm{S} 1$.

For the derivation of HC5-EBTs, it is impossible to generate the SSD curves using data for different compounds, because the toxicity data of all compounds that trigger a bioassay response have to be included. Therefore, the bioassay response of the tested wastewater was expressed as the BEQ (the concentration of the reference compounds with the same biological response) using Equation (2). The HC5 value of the reference compound was then estimated using the SSD. This approach considers all compounds that trigger a bioassay response, as well as all species that need to be protected in the aquatic environment (Oost et al., 2017). The derivation of HC5 for phenol, diuron, 4-NQO and E2 are described in SI Section S1, and their values are presented in SI Table S5.

\section{Results and discussion}

\subsection{Residual TOPs and biotoxicity for the WWTP effluent}

The chemical analysis showed that 40 out of the 48 targeted chemicals, including 2 EDCs, 6 herbicides, 6 insecticides, 5 bactericides, 13 pharmaceuticals, 5 UV filters, and 3 FRs, were detected in the SE (SI Table S6). The total concentration of TOPs in the SE ranged from $1244.54 \mathrm{ng} / \mathrm{L}$ to $1735.93 \mathrm{ng} / \mathrm{L}$. The concentration of residual TOPs in the SE depends on the biodegradability of chemicals and treatment capacity of secondary biological treatment processes. As shown in Fig. 1a, the total concentrations of EDCs, herbicides and insecticides were detected in SE at low concentration, which was in accordance with published studies (Miège et al., 2009; Petrie et al., 2015; Qi et al., 2015; Manoli et al., 2019). Among the seven categories of TOPs, bactericides and pharmaceuticals were the main components in the SE, whose total concentrations were 508.6 and $691.3 \mathrm{ng} / \mathrm{L}$, respectively (Fig. 1a). Many studies have indicated the high contents of pharmaceuticals and bactericides (especially carbendazim) in SE (Kupper et al., 2006; Miège et al., 2009; Qi et al., 2015). However, the concentration of pharmaceuticals and pesticides (herbicides, insecticides, and bactericides) in SE varied distinctly in different countries and regions, and were related to the circumstances of counter sales and application events (Miège et al., 2009; Luo et al., 2014). FRs were also detected at high concentration in the published studies, even higher than $1000 \mathrm{ng} / \mathrm{L}$ (Wei et al., 2015; Pantelaki and Voutsa, 2019).

Fig. $1 \mathrm{~b}$ shows the $\mathrm{BEQ}_{\text {phenol }}, \mathrm{BEQ}_{4-\mathrm{NQO}}$, and $\mathrm{BEQ}_{\text {diuron }}$ of $\mathrm{SE}$ was $10.59 \mathrm{mg} / \mathrm{L}, 3.80 \mu \mathrm{g} / \mathrm{L}$, and $70.37 \mathrm{ng} / \mathrm{L}$, respectively. The estrogenic (a)

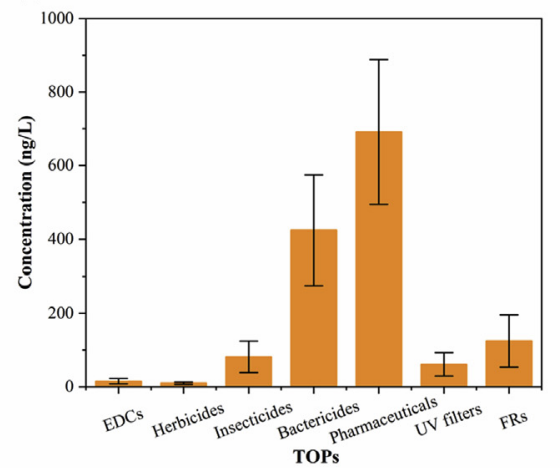

(b)

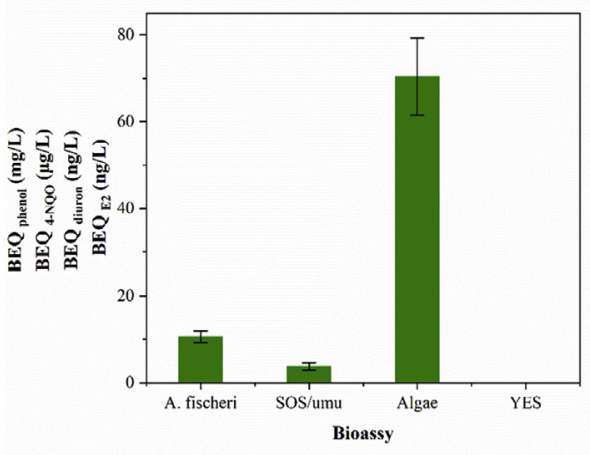

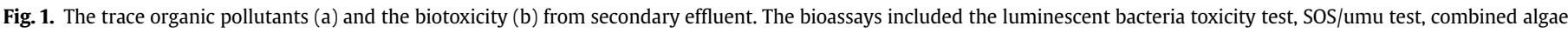
test, and YES assay. 
activity of SE was not detected at the highest REF of 500 (the detection limit of the YES assay was lower than $0.08 \mathrm{ng} / \mathrm{LBEQ}_{\mathrm{E} 2}$ ). It needs to be noted that there is limited knowledge regarding the effects of individual trace organic pollutants and their relationship to the overall mixture effect in water samples. So, researchers tried to fingerprint selected representative trace organic pollutants and their contribution to an effect from tested water samples (Neale et al., 2017). The results of luminescent bacteria toxicity tests, reflecting the non-specific bacterial cytotoxicity, were posed by the large number of non-specifically acting chemicals in the wastewater. It has been revealed that even the most thorough chemical analysis can explain only a small fraction of the observed nonspecific toxicity effects, as well as the SOS/umu test results (Tang et al., 2014b). There is lack of data for the SOS/umu test results of emerging TOPs. Reifferscheid and Heil investigated the SOS/umu test results of 486 chemicals and compared them with the results of the Ames test, suggesting a concordance of approximately $90 \%$ between the SOS/umu test and Ames test results (Reifferscheid and Heil, 1996). Thus, in the present study, the results of the Ames test (without S9) for all detected TOPs were predicted using established databases to confirm the direct-acting mutagens, such as CASE Ultra, Leadscope, and SciQSAR. These prediction results are summarized in SI Table S6 to roughly reveal the genotoxicity of the detected TOPs obtained from the SOS/umu test. The chemicals for which positive prediction results were obtained in any database were conservatively defined as having genotoxic effects.

For the responsible chemicals to the biological effects with a specific mode of action, six triazine herbicides which are wellknown as PSII inhibitors, impact algal photosynthesis and contribute the most to responses in the combined algae test (Vermeirssen et al., 2010). Two of the detected EDCs, including E1 and BPA, had estrogenic potencies (E2 equivalents) of 0.053 and $3.0 \times 10^{-5}$, respectively, based on the YES bioassay (Yao et al., 2018). Their low estrogenic potency and low detected concentrations accounted for the undetected estrogenic activity of SE, although some pesticides and UV filters have weak estrogenic activity (McKinlay et al., 2008; Zhang et al., 2017).

\subsection{Biotoxicity reduction efficiency during the advanced treatments}

Fig. 2a shows the reduction efficiency of the biotoxicity posed by SE after the coagulation process. Regarding the results of the luminescent bacteria toxicity test and combined algae test, it can be seen that no significant biotoxicity reduction ( $<30 \%$ reduction) was observed for bacterial cytotoxicity and photosynthesis inhibition in the coagulation process along with the increase of $\mathrm{PACl}$ dose $(20-400 \mathrm{mg} / \mathrm{L})$. However, the removal of $\mathrm{BEQ}_{4-\mathrm{NQO}}$ rose with the increase of $\mathrm{PACl}$ dose and maintained at a high level (50\%-75\%), suggesting that the coagulation process performed well to reduce genotoxicity. Its reduction exhibited a strong positive correlation with the PACl dose $\left(R^{2}=0.98\right.$; SI Fig. S2a). However, Chen et al. (2017) reported that the genotoxicity of SE showed no significant changes during coagulation treatment with $20 \mathrm{mg} / \mathrm{L}$ of PACl. This may be attributed to the high $U_{254}$ value of $S E\left(0.3 \mathrm{~cm}^{-1}\right.$ in the previous study versus $0.137 \mathrm{~cm}^{-1}$ in this study) and its low $\mathrm{UV}_{254}$ reduction after coagulation in their study. This may be related to the fact that $\mathrm{UV}_{254}$, as an indicator for aromatic compounds, has been found to show a good positive correlation with genotoxicity (Grandclément et al., 2017), as also found in the present study (SI Fig. S2b).

In the GAC adsorption process, the reduction efficiency of the three biotoxicities posed by SE improved with increasing GAC addition, reaching a nearly stable state with the addition of $20 \mathrm{~g} / \mathrm{L}$ of GAC (Fig. 2b). The GAC adsorption process led to the elimination of $86 \%$ of bacterial cytotoxicity, $94 \%$ of genotoxicity, and $85 \%$ of photosynthesis inhibition at the highest GAC dose used. The GAC adsorption process showed promising performance in the reduction of biotoxicity, including bacterial cytotoxicity, genotoxicity, and photosynthesis inhibition. Comparably, Macova et al. (2010) stated that approximately $68 \%$ of bioluminescence inhibition, $87 \%$ of genotoxicity, and $75 \%$ of photosynthesis inhibition could be decreased by a biological activated carbon treatment process. However, Wei et al. (2012) reported that a $28 \%$ reduction of $\mathrm{BEQ}_{\mathrm{Hg}}^{2+}$ for bacterial cytotoxicity and a $47 \%$ reduction of $\mathrm{BEQ}_{4-\mathrm{NOO}}$ for genotoxicity were achieved by an activated carbon adsorption process. Thus, promotion measures, such as increasing the addition of GAC, may be needed to reduce the biotoxicity of wastewater in the GAC adsorption process.

For UV photolysis, no significant bacterial cytotoxicity reduction was observed $(<20 \%$ reduction) with any irradiation time $(0-8 \mathrm{~h})$, even showing a slight increase ( $10 \%$ increase) at the initial stage (Fig. 2c). The removal of $\mathrm{BEQ}_{4-\mathrm{NQO}}$ and $\mathrm{BEQ}_{\text {diuron }}$ could achieve $75 \%$ and $81 \%$ respectively, suggesting that the UV photolysis process performed well in reducing genotoxicity and photosynthesis inhibition. Compared with UV photolysis, the UV photocatalysis process improved the reduction efficiency of bacterial cytotoxicity by up to $38 \%$ with a low irradiation intensity (Fig. 2d), and up to $62 \%$ with a high irradiation intensity (Fig. 2e). Therefore, the UV photocatalysis process with high irradiation intensity showed more promising results related to biotoxicity reduction. It was reported that the biotoxicity reduction efficiency of UV photolysis could reach up to $71 \%$ for bacterial cytotoxicity, $35 \%$ for photosynthesis inhibition, and $-35 \%$ for genotoxicity in full-scale treatment plants (Jia et al., 2015). Zhang et al. also revealed that medium pressure UV oxidation can induce genotoxicity and low-pressure UV treatment does not induce genotoxicity (Zhang et al., 2019). The observed difference in the biotoxicity reduction efficiency between previous studies and the present study might be attributed to the UV lamp, irradiation intensity and the highly variable types and concentrations of pollutants in the wastewater (Jia et al., 2015).

The reduction efficiency of three biotoxicities improved along with the increase of the ozone dosage addition. After $1.31 \mathrm{gO}_{3} /$ gDOC of ozonation treatment (Fig. 2f), the $\mathrm{BEQ}_{\text {phenol, }} \mathrm{BEQ}_{4-\mathrm{NQO}}$ and $\mathrm{BEQ}_{\text {diuron }}$ of SE were decreased to the levels below their limit of detection. This suggested that the ozonation process performed well in the reduction of bacterial cytotoxicity, genotoxicity and photosynthesis inhibition. Previous studies showed that ozonation provided conclusive advantages in the reduction of multiple biological effects. Ozonation could reduce approximately $30 \%$ bacterial cytotoxicity using $V$. fischeri or the rat pituitary cell line GH3 (Reungoat et al., 2011; Stalter et al., 2011), > 79\% genotoxicity using the SOS/umu test (Tang et al., 2014a; Magdeburg et al., 2014), and approximately 35\% photosynthesis inhibition (Jia et al., 2015). In addition, endocrine activities (e.g., estrogenicity, androgenicity, anti-androgenicity, and aryl-hydrocarbon receptor agonistic activity) could be effectively reduced by an ozonation process (Stalter et al., 2011; Altmann et al., 2012). However, the toxicity reduction efficiency was ozone-dose dependent, and the increased biotoxicity probably exhibited at the low ozone-dose owing to the incomplete oxidation and ozonation by-products generation (Jia et al., 2015).

Overall, non-specific bacterial cytotoxicity was the most resistant biotoxicity to be reduced by the ATPs, in contrast with reactive genotoxicity and specific photosynthesis inhibition. GAC adsorption and ozonation are the preferred options to reduce the three biotoxicities. It should be noted that UV photolysis and photocatalysis showed comparable efficiencies for the reduction of genotoxicity and photosynthesis inhibition, and UV photocatalysis could improve the reduction of bacterial cytotoxicity. Meanwhile, coagulation only performed well in the reduction of genotoxicity. This revealed the selectivity of biotoxicity reduction during different types of ATPs. 
(a)
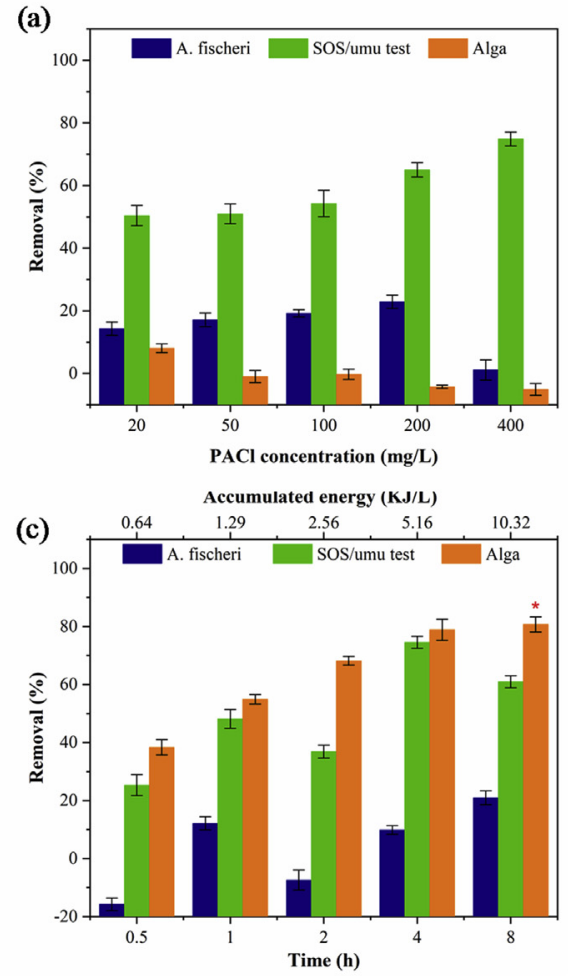

(e)

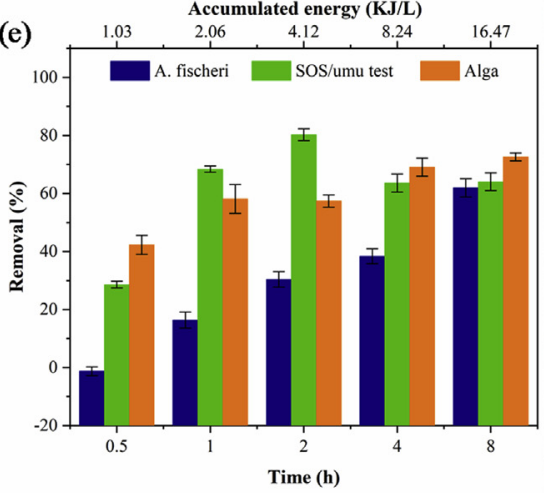

(b)

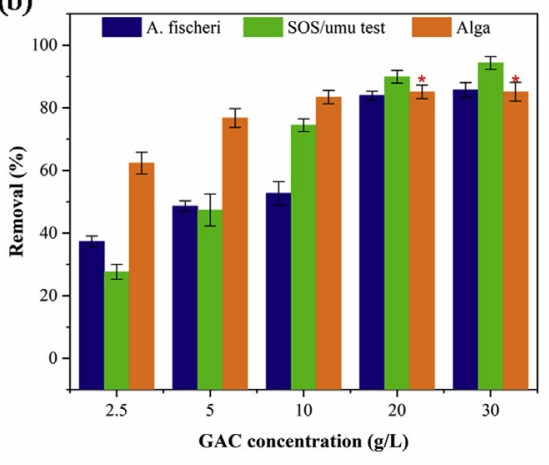

(d)

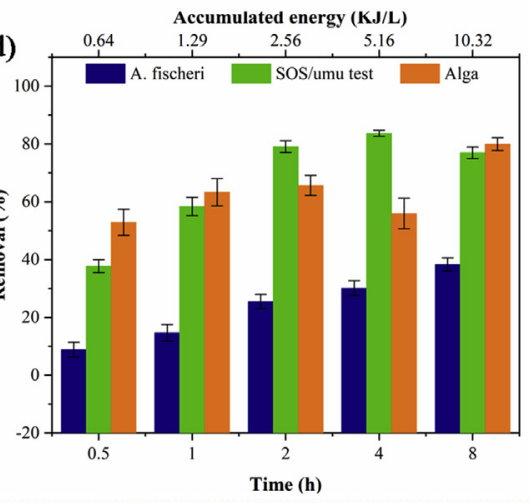

(f)

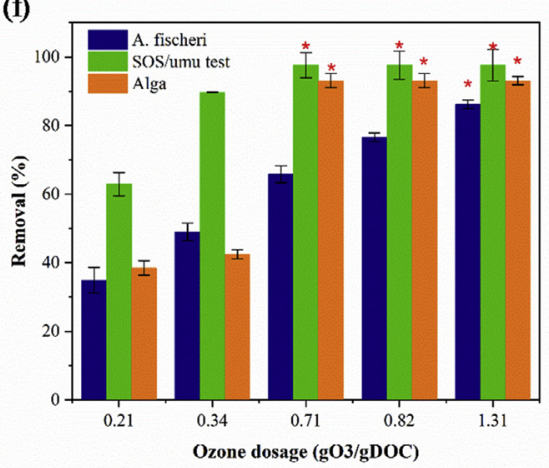

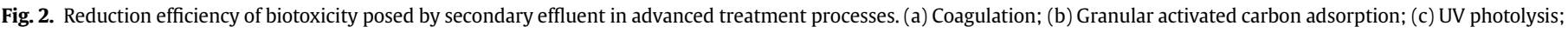

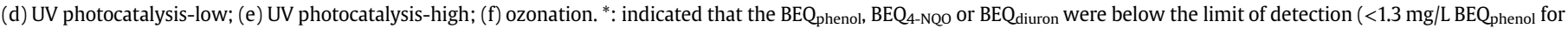
the luminescent bacteria toxicity test; $<0.15 \mu \mathrm{g} / \mathrm{LBEQ}_{4-\mathrm{NQO}}$ for the SOS/umu test; and $<4.2 \mathrm{ng} / \mathrm{L}$ BEQ $\mathrm{diuron}_{\text {for }}$ the combined algae test).

\subsection{The treatability of TOPS}

The removal of TOPs (total concentration) detected in SE was below $10 \%$ and fluctuated in a small range during $20-400 \mathrm{mg} / \mathrm{L}$ of $\mathrm{PACl}$ coagulation treatment process (Fig. 3). After treatment with $400 \mathrm{mg} / \mathrm{L}$ of PACl, the removal of all seven categories of chemicals was below 15\% (Fig. 4). There were also poor removal efficiencies achieved for all individual TOPs (Fig. 5). The reason that the coagulation process showed a good performance for genotoxicity removal (75\% reduction at the $\mathrm{PACl}$ dose of $400 \mathrm{mg} / \mathrm{L}$ ) may be attributed to the reduction of the chemicals with genotoxic effects, such as atrazine, acetamiprid, roxithromycin sulfamethoxazole, and carbamazepine (Figs. 4 and SI Table S6), as well as the decrease of DOM with fluorescence (Chen et al., 2017).

The removal of TOPs improved along with GAC addition and reached up to $79 \%$ under $30 \mathrm{~g} / \mathrm{L}$ of GAC addition (Fig. 3). The removal of seven categories of chemicals, comprising EDCs, herbicides, insecticide, bactericide, pharmaceuticals, UV filters, and FRs were $97 \%, 81 \%, 87 \%, 93 \%, 74 \%, 72 \%$, and $80 \%$, respectively (Fig. 4). Pharmaceuticals were the dominant components residual in the treated wastewater, because the removals of diclofenac acid, ibuprofen, mefenamic acid, clarithromycin, roxithromycin and sulfamethoxazole were all below 80\% (Fig. 5). Activated carbon adsorption was based on non-specific dispersive interplays and intricate reactions between TOPs and functional groups on the surfaces of the adsorbents (Han et al., 2015). These characteristics of non-specific adsorption make it rationalization for achieving the remarkable three biotoxicity reduction efficiency after GAC adsorption.

Comparing UV photolysis with UV photocatalysis-low and -high processes, the removal of TOPs increased when the Degussa P25type $\mathrm{TiO}_{2}$ was added and the irradiation intensity was enhanced (Fig. 3). In the UV photolysis process under $8 \mathrm{~h}$ of irradiation, EDCs, herbicides, bactericides and pharmaceuticals were removed with high efficiencies ( $>75 \%$ removal), while insecticides, UV filters and 


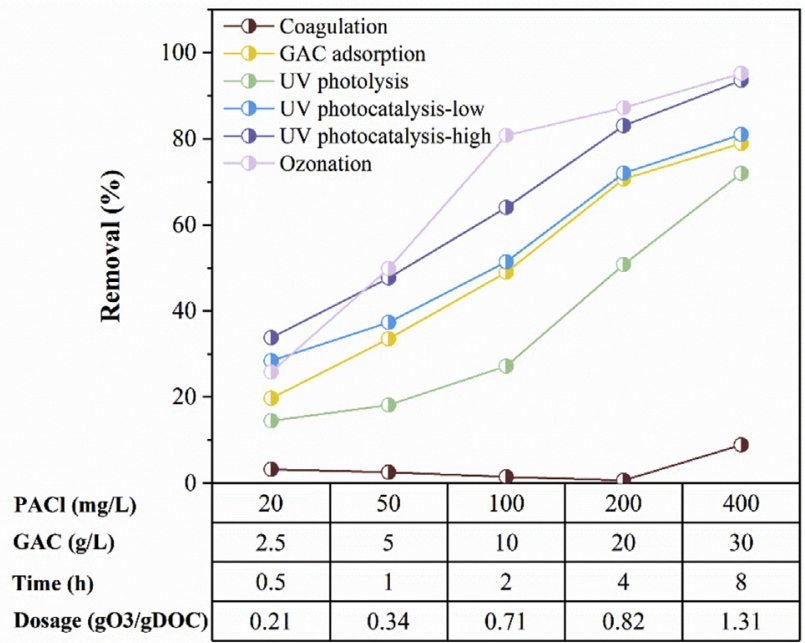

Fig. 3. Removal of trace organic pollutants (total concentration) in secondary effluent after advanced treatment.

FRs were removed with low efficiencies (Fig. 4). When the Degussa P25-type $\mathrm{TiO}_{2}$ was added, the removal efficiency of all seven categories of TOPs was increased relative to these in the UV photolysis process, except for EDCs and UV filters. The decreased removal efficiency of EDCs was attributed to the low removal of BPA (Fig. 5). The UV photolysis and photocatalytic process performed in the complex matrix of the secondary effluent. It was pointed out that the compounds which could increase BPA degradation during UV photolysis in the wastewater, such as DOM, carbonate, nitrate and nitrite, may cause the inactivation of active sites on the catalyst, inhibiting BPA elimination by photocatalysis (Jiménez-Tototzintle et al., 2018; Kang et al., 2018; Yang et al., 2018). The removal of UV filters remained stable, and even the irradiation intensity was enhanced. Under the high irradiation intensity, the removal of TOPs was generally improved, especially for insecticides (Fig. 4). This may explain the improved capacity of UV photocatalysis processes for non-specific bacterial cytotoxicity. Considering the removal of individual chemical, dipterex, carbendazim, dimethomorph, clarithromycin, roxithromycin, trimethoprim, carbamazepin, BP4, TPeP, and TBP, which were removed with low efficiencies in the UV photolysis processes, could be further removed by UV photocatalysis processes (Fig. 5).

Ozonation could remove a wide range of TOPs, either by undergoing a direct reaction with ozone or indirectly after the formation of hydroxyl radicals (Reungoat et al., 2011; Luo et al., 2014). The removal of TOPs increased along with the ozone dosage addition, and reached up to $93.57 \%$ at the $1.31 \mathrm{gO}_{3} / \mathrm{gDOC}$ ozone dosage (Fig. 3). As shown in Fig. 4, all seven categories of chemicals could be removed with high efficiencies ( $>90 \%$ reduction), except insecticides (62\% reduction) and UV filters ( $71 \%$ reduction). For individual chemicals, dichlorvos, dipterex, acetamiprid, BP3, OC, EHMC, and TPPO could not be decreased with relative high efficiency $(<80 \%)$ by ozonation (Fig. 5). Switzerland has recently introduced nation-wide ozonation of wastewater to maximize trace organic pollutants removal from the effluent of WWTP. Thus, the promising treatability of TOPs in wastewater by the ozonation process is widely accepted. Although partial chemicals had relatively low reduction in the ozonation process, non-specific bacterial cytotoxicity could be decreased effectively. The chemicals that were not detected by the applied chemical analysis procedures were probably responsible for the three detected biotoxicities (Chen et al., 2017). However, it is impractical to investigate all the chemicals that are responsible for the biological effects from SE, especially for non-specific toxicity. This also reflects the significance of bioassays for ecological safety. Additionally, considering the limited extractability of SPE regarding polar ozonation byproducts, the biotoxicity of wastewater after ozonation may be underestimated (Stalter et al., 2011).

On the whole, the removal of TOPs during the four types of ATPs was accompanied by biotoxicity reduction. For the seven categories of chemicals, EDCs were readily degraded by GAC adsorption, UV photolysis and ozonation. Herbicides and bactericides were readily degraded by three types of ATPs, except coagulation. Only GAC adsorption performed well in the removal of insecticides. Pharmaceuticals were effectively removed by UV photolysis and photocatalysis, and ozonation; FRs could be removed during GAC adsorption and ozonation with high efficiency. However, UV filters were relatively resistant to removal during all four types of ATPs.

\subsection{Strategies for biotoxicity control based on EBTs}

Presently, no worldwide agreement has yet been reached regarding what level of bioassay response is acceptable. Considering ecological risks, EQS-EBTs and HC5-EBTs were used to assess and prioritize the ATPs. The biotoxicity of wastewater subjected to one ATP may be reduced with low efficiency, but may actually present no potential ecological health risk. In contrast, a process with a high removal efficiency of biotoxicity may result in effluent that still poses high ecological risks. In SI Figs. S3 and S4, the four types of ATPs for biotoxicity reduction were assessed based on their EQS-EBTs and HC5-EBTs, respectively. In SI Fig. S4, the most conservative value based on the $95 \%$ confidence intervals of HC5 was used in the consideration of ecological safety. The assessment results collected from SI Figs. S3 and S4 are summarized in Table 2. It was firstly revealed that the assessment results using EQS-EBTs were consistent with those using HC5-EBTs (Table 2).

To guarantee ecological safety, the non-specific bacterial cytotoxicity posed by SE could only be reduced through $\geq 20 \mathrm{~g} / \mathrm{L}$ of GAC adsorption or ozonation with $\geq 0.71 \mathrm{gO}_{3} / \mathrm{gDOC}$ of ozone dosage. The genotoxicity from SE could be reduced to an ecologically safe level by $\geq 20 \mathrm{~g} / \mathrm{L}$ of GAC adsorption, ozonation with $\geq 0.34 \mathrm{gO}_{3} / \mathrm{gDOC}$ of ozone dosage, or UV photocatalysis. It was difficult to identify and control the parameters of UV photocatalysis to achieve ecological safety, because the biotoxicity reduction varied irregularly during the UV photocatalysis process, probably due to the variations in oxidation by-products. The photosynthesis inhibition and estrogenic activity resulting from SE were weak enough to be considered negligible, because an ecologically safe level of this endpoint could be achieved without any treatment most of time. Certainly, the biotoxicity of SE is not the only indicator that should be used to select ATPs. When the quality of wastewater meets the relevant wastewater discharge standards, bioassays should be proposed to achieve further protection of aquatic environments.

\section{Conclusions}

This study assessed the treatability of TOPs and associated biotoxicity reduction by four different types of ATPs, and applied EQSEBT and HC5-EBT values to discuss whether acceptable biotoxicity reductions can be achieved by them. GAC adsorption and ozonation were the most promising processes for the reduction of bacterial cytotoxicity, genotoxicity, and photosynthesis inhibition; UV photolysis and photocatalysis also had the capacity to reduce genotoxicity and photosynthesis inhibition. Meanwhile, the four types of ATPs showed different treatability for seven categories of TOPs. Generally, EDCs, herbicides, bactericides, and pharmaceuticals were readily removed, and insecticides, FRs, and UV filters 

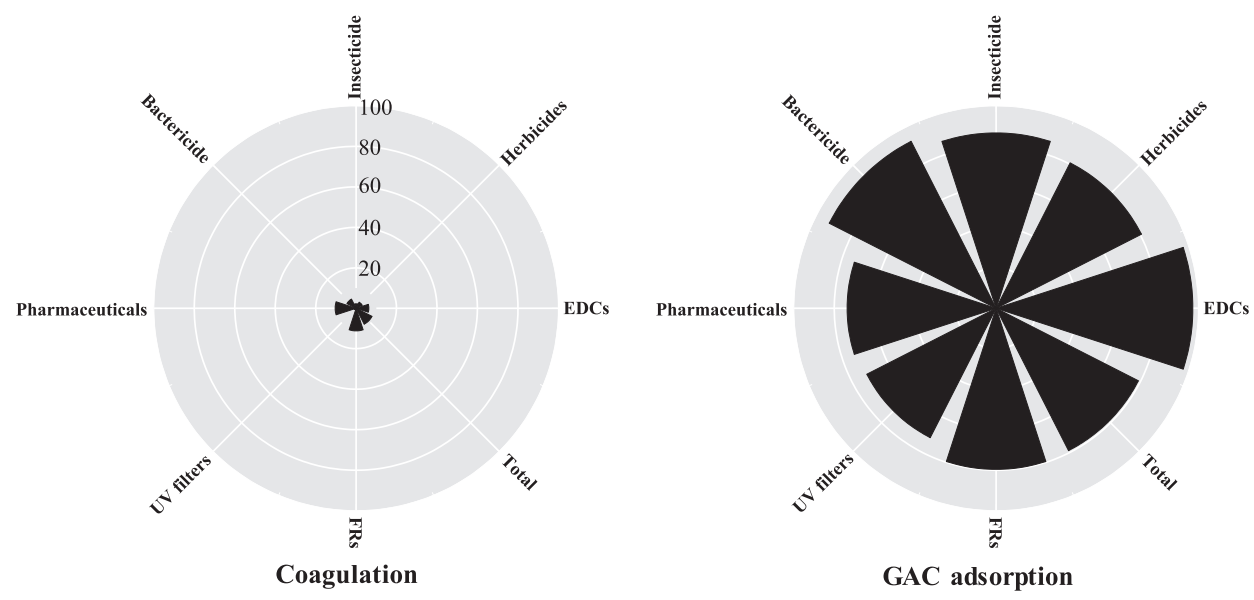

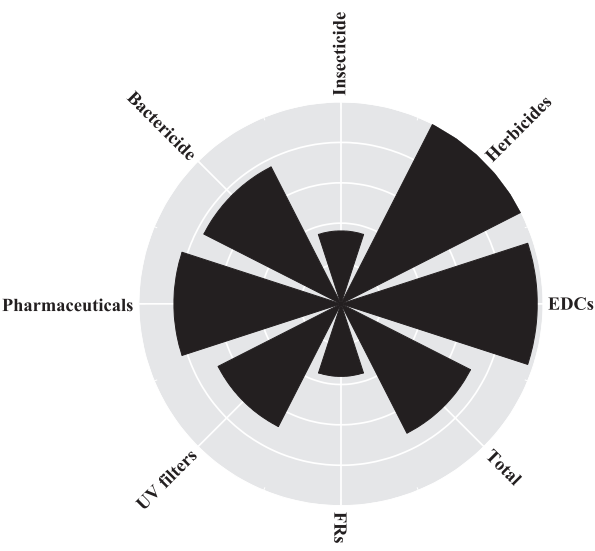

UV photolysis

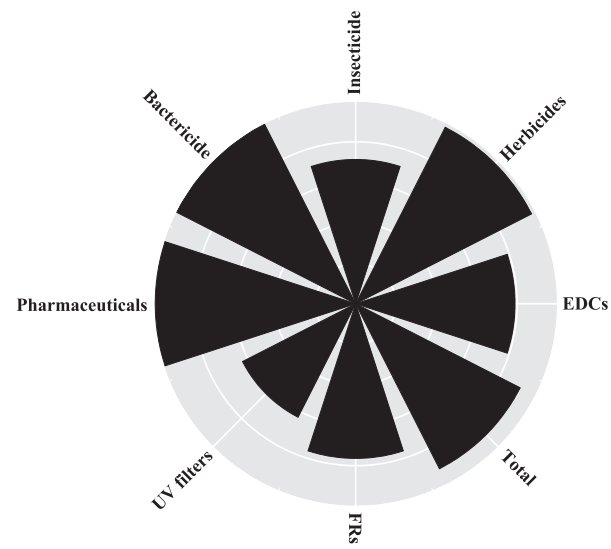

UV photocatalysis-high

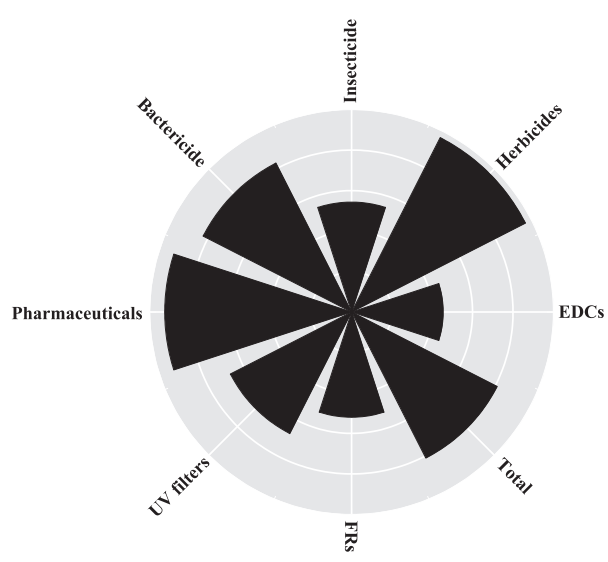

UV photocatalysis-low

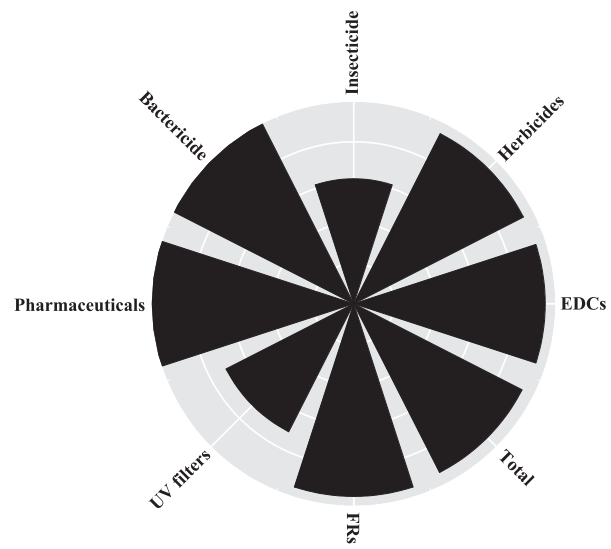

Ozonation

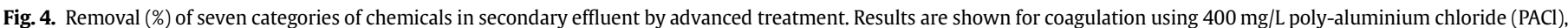

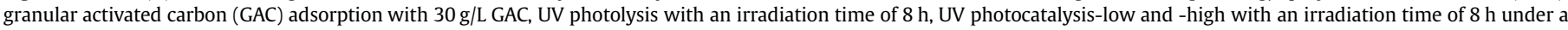
low or high irradiation intensity, respectively, ozonation with a ozone dosage of $1.31 \mathrm{gO}_{3} / \mathrm{gDOC}$.

were relatively refractory. It should be noted that the TOPs detected in SE in the present study did not include all the chemicals in the EU EQS. Thus, an improved water quality standard is also appealed for environmental protection.

Adequately defining EBTs requires substantial toxicological data, especially for the chemicals in the existing list of EQS. This impedes EBT derivation and reduces its accuracy. In many countries and regions, the existing EQS does not include potent chemicals that have clear biological effects of environmental concern. Hence, the
EBTs derived from the existing European Union EQS were used in the present study. The assessment results made using EQS-EBTs were similarly consistent with those made using HC5-EBTs. These assessment results should be beneficial for efforts to prioritize the ATPs and optimize the operating parameters. In the future, to reduce the negative effects of WWTP effluent on the receiving water bodies, advanced treatments should be used in more appropriate ways, and bioassays with different endpoints should be integrated with chemical analyses to better monitor water quality. 


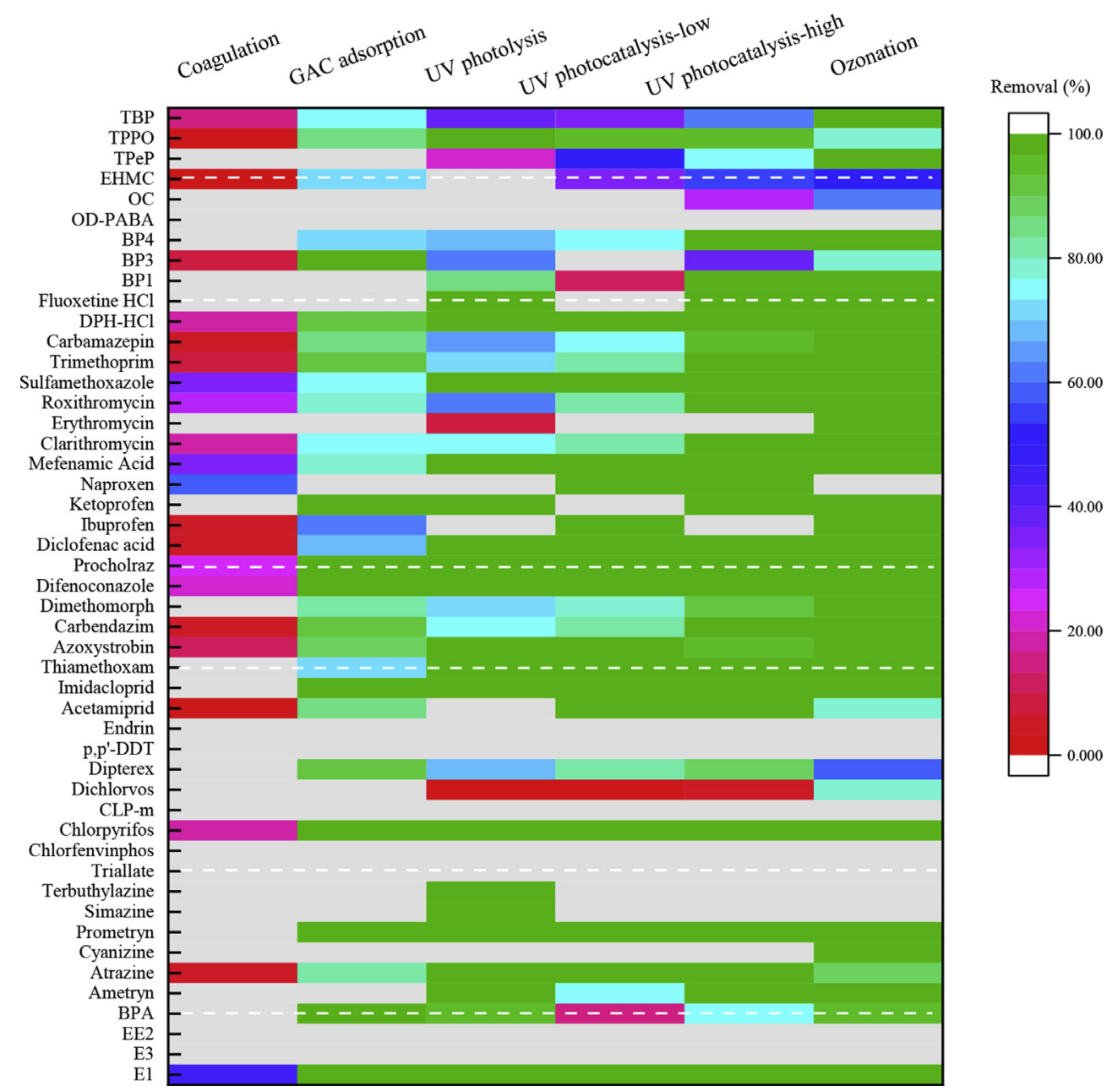

Fig. 5. The fingerprint of the removal of individual trace organic pollutants during advanced treatment processes. The results are shown for coagulation using $400 \mathrm{mg} / \mathrm{L}$ of polyaluminum chloride (PACl), granular activated carbon (GAC) adsorption with $30 \mathrm{~g} / \mathrm{L}$ of GAC, UV photolysis with an irradiation time of $8 \mathrm{~h}$, UV photocatalysis-low and -high with an irradiation time of $8 \mathrm{~h}$ under a low or high irradiation intensity, respectively, and ozonation with an ozone dosage of $1.31 \mathrm{gO3/gDOC}$. The gray color indicates missing values, suggesting that the chemicals were not detected in the samples. (For interpretation of the references to color in this figure legend, the reader is referred to the Web version of this article.)

Table 2

Assessment results of advanced treatment processes based on the EQS-EBTs and HC5-EBTs.

\begin{tabular}{llllll}
\hline Advanced treatment & Assessment method & Biouminescece inhibition & Genotoxicity & Photosynthesis inhibition & Estrogenic activity \\
\hline Coagulation & EQS-EBT & Unacceptable & Unacceptable & - & - \\
& HC5-EBT & Unacceptable & Unacceptable & - & - \\
GAC adsorption & EQS-EBT & $\geq 20 \mathrm{~g} / \mathrm{L} \mathrm{GAC}$ & $\geq 20 \mathrm{~g} / \mathrm{L} \mathrm{GAC}$ & - & - \\
& HC5-EBT & $\geq 20 \mathrm{~g} / \mathrm{L} \mathrm{GAC}$ & $\geq 20 \mathrm{~g} / \mathrm{L} \mathrm{GAC}$ & - & - \\
UV photolysis & EQS-EBT & Unacceptable & Unacceptable & $\geq 0.5 \mathrm{~h} \mathrm{UV}(0.64 \mathrm{~kJ} / \mathrm{L})$ & - \\
& HC5-EBT & Unacceptable & Unacceptable & - & - \\
UV photocatalysis-low & EQS-EBT & Unacceptable & $4 \mathrm{~h} \mathrm{UV}(5.16 \mathrm{~kJ} / \mathrm{L})$ & $\geq 0.5 \mathrm{~h} \mathrm{UV}(0.64 \mathrm{~kJ} / \mathrm{L})$ & - \\
& HC5-EBT & Unacceptable & $\geq 2 \mathrm{~h} \mathrm{UV}(2.56 \mathrm{~kJ} / \mathrm{L})$ & - & - \\
UV photocatalysis-high & EQS-EBT & Unacceptable & $2 \mathrm{~h} \mathrm{UV}(4.12 \mathrm{~kJ} / \mathrm{L})$ & $\geq 0.5 \mathrm{~h} \mathrm{UV}(1.03 \mathrm{~kJ} / \mathrm{L})$ & - \\
& HC5-EBT & $8 \mathrm{~h} \mathrm{UV}$ & $2 \mathrm{~h} \mathrm{UV}(4.12 \mathrm{~kJ} / \mathrm{L})$ & - & - \\
Ozonation & EQS-EBT & $\geq 0.71 \mathrm{gO}_{3} / \mathrm{gDOC}$ & $\geq 0.34 \mathrm{gO}_{3} / \mathrm{gDOC}$ & - & - \\
& HC5-EBT & $\geq 0.34 \mathrm{gO}_{3} / \mathrm{gDOC}$ & $\geq 0.34 \mathrm{gO}_{3} / \mathrm{gDOC}$ & - & \\
\hline
\end{tabular}

$-:$ means that the biotoxicity from SE exceeded the EQS-EBT or below HC5-EBT without any treatment. This indicated that the wastewater achieved the level of ecological safety without any treatment.

\section{Acknowledgements}

This study was supported by the National Natural Science Foundation of China (Grant No. 51508449, 51778522), and Scientific Research Program Funded by the Shaanxi Provincial Education Department, China (No. 18JK0468).

\section{Appendix A. Supplementary data}

Supplementary data to this article can be found online at https://doi.org/10.1016/j.watres.2019.05.011. 


\section{References}

Altmann, D., Schaar, H., Bartel, C., Schorkopf, D.L.P., Miller, I., Kreuzinger, N., Möstl, E., Grillitsch, B., 2012. Impact of ozonation on ecotoxicity and endocrine activity of tertiary treated wastewater effluent. Water Res. 46 (11), 3693-3702.

Chen, Z., Li, M., Wen, Q., 2017. Comprehensive evaluation of three sets of advanced wastewater treatment trains for treating secondary effluent: organic micropollutants and bio-toxicity. Chemosphere 189, 426-434.

Daniels, K.D., VanDervort, D., Wu, S., Leusch, F.D.L., van de Merwe, J.P., Jia, A., Snyder, S.A., 2018. Downstream trends of in vitro bioassay responses in a wastewater effluent-dominated river. Chemosphere 212, 182-192.

Escher, B.I., Aït-Aïssa, S., Behnisch, P.A., Brack, W., Brion, F., Brouwer, A., Buchinger, S., Crawford, S.E., Du Pasquier, D., Hamers, T., Hettwer, K., Hilscherová, K., Hollert, H., Kase, R., Kienle, C., Tindall, A.J., Tuerk, J., van der Oost, R., Vermeirssen, E., Neale, P.A., 2018. Effect-based trigger values for in vitro and in vivo bioassays performed on surface water extracts supporting the environmental quality standards (EQS) of the European Water Framework Directive. Sci. Total Environ. 628-629, 748-765.

Escher, B.I., Allinson, M., Altenburger, R., Bain, P.A., Balaguer, P., Busch, W., Crago, J., Denslow, N.D., Dopp, E., Hilscherova, K., Humpage, A.R., Kumar, A., Grimaldi, M., Jayasinghe, B.S., Jarosova, B., Jia, A., Makarov, S., Maruya, K.A., Medvedev, A., Mehinto, A.C., Mendez, J.E., Poulsen, A., Prochazka, E., Richard, J., Schifferli, A., Schlenk, D., Scholz, S., Shiraish, F., Snyder, S., Su, G.Y., Tang, J.Y.M., van der Burg, B., van der Linden, S.C., Werner, I., Westerheide, S.D., Wong, C.K.C., Yang, M., Yeung, B.H.Y., Zhang, X.W., Leusch, F.D.L., 2014. Benchmarking organic micropollutants in wastewater, recycled water and drinking water with in vitro bioassays. Environ. Sci. Technol. 48 (3), 1940-1956.

Escher, B.I., Neale, P.A., Leusch, F.D.L., 2015. Effect-based trigger values for in vitro bioassays: reading across from existing water quality guideline values. Water Res. 81, 137-148.

Fournier, M.-L., Echeverría-Sáenz, S., Mena, F., Arias-Andrés, M., de la Cruz, E., Ruepert, C., 2018. Risk assessment of agriculture impact on the frío river watershed and caño negro ramsar wetland, Costa Rica. Environ. Sci. Pollut. Control Ser. 25 (14), 13347-13359.

Freitas, A.M., Rivas, G., Camposmañas, M.C., Casas López, J.L., Agüera, A., Sánchez Pérez, J.A., 2016. Ecotoxicity evaluation of a WWTP effluent treated by solar photo-Fenton at neutral $\mathrm{pH}$ in a raceway pond reactor. Environ. Sci. Pollut. Res. 24 (2), 1093-1104.

Gavrilescu, M., Demnerová, K., Aamand, J., Agathos, S., Fava, F., 2015. Emerging pollutants in the environment: present and future challenges in biomonitoring, ecological risks and bioremediation. N. Biotech. 32 (1), 147-156.

Grandclément, C., Seyssiecq, I., Piram, A., Wong-Wah-Chung, P., Vanot, G. Tiliacos, N., Roche, N., Doumenq, P., 2017. From the conventional biological wastewater treatment to hybrid processes, the evaluation of organic micropollutant removal: a review. Water Res. 111, 297-317.

Han, O., Yan, H., Zhang, F., Xue, N., Wang, Y., Chu, Y., Gao, B., 2015. Trihalomethanes (THMs) precursor fractions removal by coagulation and adsorption for biotreated municipal wastewater: molecular weight, hydrophobicity/hydrophily and fluorescence. J. Hazard Mater. 297, 119-126.

Hashmi, M.A.K., Escher, B.I., Krauss, M., Teodorovic, I., Brack, W., 2018. Effectdirected analysis (EDA) of Danube River water sample receiving untreated municipal wastewater from Novi Sad, Serbia. Sci. Total Environ. 624C, 1072-1081.

Jarošová, B., Bláha, L., Giesy, J.P., Hilscherová, K., 2014. What level of estrogenic activity determined by in vitro assays in municipal waste waters can be considered as safe? Environ. Int. 64, 98-109.

Jia, A., Escher, B.I., Leusch, F.D.L., Tang, J.Y.M., Prochazka, E., Dong, B., Snyder, E.M., Snyder, S.A., 2015. In vitro bioassays to evaluate complex chemical mixtures in recycled water. Water Res. $80,1-11$.

Jiménez-Tototzintle, M., Ferreira, I.J., da Silva Duque, S., Guimarães Barrocas, P.R. Saggioro, E.M., 2018. Removal of contaminants of emerging concern (CECs) and antibiotic resistant bacteria in urban wastewater using $\mathrm{UVA} / \mathrm{TiO}_{2} / \mathrm{H}_{2} \mathrm{O}_{2}$ photocatalysis. Chemosphere 210, 449-457.

Kang, Y.-M., Kim, M.-K., Zoh, K.-D., 2018. Effect of nitrate, carbonate/bicarbonate, humic acid, and $\mathrm{H}_{2} \mathrm{O}_{2}$ on the kinetics and degradation mechanism of BisphenolA during UV photolysis. Chemosphere 204, 148-155.

Kasprzyk-Hordern, B., Raczyk-Stanisławiak, U., Swietlik, J., Nawrocki, J., 2006. Catalytic ozonation of natural organic matter on alumina. Appl. Catal. B Environ. 62 (3), 345-358.

Kupper, T., Plagellat, C., Brändli, R.C., de Alencastro, L.F., Grandjean, D., Tarradellas, J., 2006. Fate and removal of polycyclic musks, UV filters and biocides during wastewater treatment. Water Res. 40 (14), 2603-2612.

Leusch, F.D.L., Khan, S.J., Laingam, S., Prochazka, E., Froscio, S., Trinh, T., Chapman, H.F. Humpage, A., 2014. Assessment of the application of bioanalytical tools as surrogate measure of chemical contaminants in recycled water. Water Res. 49 (0), 300-315.

Link, M., von der Ohe, P.C., Voß, K., Schäfer, R.B., 2017. Comparison of dilution factors for German wastewater treatment plant effluents in receiving streams to the fixed dilution factor from chemical risk assessment. Sci. Total Environ. 598, 805-813.

Luo, Y., Guo, W., Ngo, H.H., Nghiem, L.D., Hai, F.I., Zhang, J., Liang, S., Wang, X.C., 2014. A review on the occurrence of micropollutants in the aquatic environment and their fate and removal during wastewater treatment. Sci. Total Environ. 473-474, 619-641.
Macova, M., Escher, B.I., Reungoat, J., Carswell, S., Chue, K.L., Keller, J., Mueller, J.F., 2010. Monitoring the biological activity of micropollutants during advanced wastewater treatment with ozonation and activated carbon filtration. Water Res. 44 (2), 477-492.

Macova, M., Toze, S., Hodgers, L., Mueller, J.F., Bartkow, M., Escher, B.I., 2011. Bioanalytical tools for the evaluation of organic micropollutants during sewage treatment, water recycling and drinking water generation. Water Res. 45 (14) 4238-4247.

Magdeburg, A., Stalter, D., Schlüsener, M., Ternes, T., Oehlmann, J., 2014. Evaluating the efficiency of advanced wastewater treatment: target analysis of organic contaminants and (geno-)toxicity assessment tell a different story. Water Res. 50, 35-47.

Ma, X.Y., Wang, X.C., Wang, D., Ngo, H.H., Zhang, Q., Wang, Y., Dai, D., 2016. Function of a landscape lake in the reduction of biotoxicity related to trace organic chemicals from reclaimed water. J. Hazard Mater. 318, 663-670.

Manoli, K., Morrison, LM. Sumarah, M.W Nakhla, G, Ray, A.K, Sharma, V.K, 2019. Pharmaceuticals and pesticides in secondary effluent wastewater: identification and enhanced removal by acid-activated ferrate(VI). Water Res. 148, 272-280.

McKinlay, R., Plant, J.A., Bell, J.N.B., Voulvoulis, N., 2008. Endocrine disrupting pesticides: implications for risk assessment. Environ. Int. 34 (2), 168-183.

Miège, C., Choubert, J.M., Ribeiro, L., Eusèbe, M., Coquery, M., 2009. Fate of pharmaceuticals and personal care products in wastewater treatment plants conception of a database and first results. Environ. Pollut. 157 (5), 1721-1726.

Neale, P.A., Altenburger, R., Aït-Aïssa, S., Brion, F., Busch, W., de Aragão Umbuzeiro, G., Denison, M.S., Du Pasquier, D., Hilscherová, K., Hollert, H., Morales, D.A., Novák, J., Schlichting, R., Seiler, T.-B., Serra, H., Shao, Y. Tindall, A.J., Tollefsen, K.E., Williams, T.D., Escher, B.I., 2017. Development of a bioanalytical test battery for water quality monitoring: fingerprinting identified micropollutants and their contribution to effects in surface water. Water Res. 123, 734-750.

Ogbeide, O., Chukwuka, A., Tongo, I., Ezemonye, L., 2018. Relationship between geosorbent properties and field-based partition coefficients for pesticides in surface water and sediments of selected agrarian catchments: implications for risk assessment. J. Environ. Manag. 217, 23-37.

Oost, R.v.d., Sileno, G., Suárez-Muñoz, M., Nguyen, M.T., Besselink, H., Brouwer, A. 2017. SIMONI (Smart Integrated Monitoring) as a novel bioanalytical strategy for water quality assessment: Part I-model design and effect-based trigger values. Environ. Toxicol. Chem. 36 (9), 2385-2399.

Ortega-Gómez, E., Martín, M.M.B., García, B.E., Pérez, J.A.S., Ibáñez, P.F., 2016 Wastewater disinfection by neutral pH photo-Fenton: the role of solar radiation intensity Appl. Catal. B Environ. 181,1-6.

Pantelaki, I., Voutsa, D., 2019. Organophosphate flame retardants (OPFRs): a review on analytical methods and occurrence in wastewater and aquatic environment. Sci. Total Environ. 649, 247-263.

Pasquini, L., Munoz, J.-F., Pons, M.-N., Yvon, J., Dauchy, X., France, X., Le, N.D., FranceLanord, C., Görner, T., 2014. Occurrence of eight household micropollutants in urban wastewater and their fate in a wastewater treatment plant. Statistical evaluation. Sci. Total Environ. 481 (0), 459-468.

Petrie, B., Barden, R., Kasprzyk-Hordern, B., 2015. A review on emerging contaminants in wastewaters and the environment: current knowledge, understudied areas and recommendations for future monitoring. Water Res, 72 (0), 3-27.

Qi, W., Singer, H., Berg, M., Müller, B., Pernet-Coudrier, B., Liu, H., Qu, J., 2015. Elimination of polar micropollutants and anthropogenic markers by wastewater treatment in Beijing, China. Chemosphere 119 (0), 1054-1061.

Reifferscheid, G., Heil, J., 1996. Validation of the SOS/umu test using test results of 486 chemicals and comparison with the Ames test and carcinogenicity data. Mutat. Res. Genet. Toxicol. 369 (3), 129-145.

Reungoat, J. Escher, B.I., Macova, M., Keller, J., 2011. Biofiltration of wastewater treatment plant effluent: effective removal of pharmaceuticals and personal care products and reduction of toxicity. Water Res. 45 (9), 2751-2762.

Silva, E., Rajapakse, N., Kortenkamp, A., 2002. Something from "nothing"-eight weak estrogenic chemicals combined at concentrations below NOECs produce significant mixture effects. Environ. Sci. Technol. 36 (8), 1751-1756.

Stalter, D., Magdeburg, A., Wagner, M., Oehlmann, J., 2011. Ozonation and activated carbon treatment of sewage effluents: removal of endocrine activity and cytotoxicity. Water Res. 45 (3), 1015-1024.

Stalter, D., Peters, L.I., O'Malley, E., Tang, J.Y., Revalor, M., Farré, M.J., Watson, K. Von, G.U., Escher, B.I., 2016. Sample enrichment for bioanalytical assessment of disinfected drinking water: concentrating the polar, the volatiles, and the unknowns. Environ. Sci. Technol. 50 (12), 6495.

Tang, J.Y.M., Busetti, F., Charrois, J.W.A., Escher, B.I., 2014. Which chemicals drive biological effects in wastewater and recycled water? Water Res. 60 (0), 289-299.

Tang, J.Y.M., Escher, B.I., 2014. Realistic environmental mixtures of micropollutants in surface, drinking, and recycled water: herbicides dominate the mixture toxicity toward algae. Environ. Toxicol. Chem. 33 (6), 1427-1436.

Tang, J.Y.M., McCarty, S., Glenn, E., Neale, P.A., Warne, M.S.J., Escher, B.I., 2013 Mixture effects of organic micropollutants present in water: towards the development of effect-based water quality trigger values for baseline toxicity. Water Res. 47 (10), 3300-3314.

Tang, J., Wang, X., Hu, Y., Zhang, Y., Li, Y., 2016. Lactic acid fermentation from food waste with indigenous microbiota: effects of $\mathrm{pH}$, temperature and high OLR Waste Manag. 52, 278-285.

Tang, X., Wu, Q., Yang, Y., Hu, H., 2014. Genotoxicity removal of reclaimed water during ozonation. J. Environ. Sci. 26 (6), 1243-1248. 
Vermeirssen, E.L.M., Hollender, J., Bramaz, N., van der Voet, J., Escher, B.I., 2010 Linking toxicity in algal and bacterial assays with chemical analysis in passive samplers deployed in 21 treated sewage effluents. Environ. Toxicol. Chem. 29 (11), 2575-2582.

Wang, J., Tian, Z., Huo, Y., Yang, M., Zheng, X., Zhang, Y., 2018. Monitoring of 943 organic micropollutants in wastewater from municipal wastewater treatment plants with secondary and advanced treatment processes. J. Environ. Sci. 67, 309-317.

Wang, W.-L., Wu, Q-Y., Huang, N., Xu, Z.-B., Lee, M.-Y., Hu, H.-Y., 2018. Potential risks from UV/H2O2 oxidation and UV photocatalysis: a review of toxic, assimilable, and sensory-unpleasant transformation products. Water Res. 141, 109-125.

Wei, D., Tan, Z., Du, Y., 2012. Toxicity-based assessment of the treatment performance of wastewater treatment and reclamation processes. J. Environ. Sci. 24 (6), 969-978.

Wei, G.-L., Li, D.-Q., Zhuo, M.-N., Liao, Y.-S., Xie, Z.-Y., Guo, T.-L., Li, J.-J., Zhang, S.-Y., Liang, Z-Q. 2015. Organophosphorus flame retardants and plasticizers: sources, occurrence, toxicity and human exposure. Environ. Pollut. 196, 29-46.

Xu, J., Zhao, C., Wei, D., Du, Y., 2014. A toxicity-based method for evaluating safety of reclaimed water for environmental reuses. J. Environ. Sci. 26 (10), 1961-1969.

Yang, S., Qiu, X., Jin, P., Dzakpasu, M., Wang, X.C., Zhang, Q., zhang, L., Yang, L.
Ding, D., Wang, W., Wu, K., 2018. MOF-templated synthesis of $\mathrm{CoFe}_{2} \mathrm{O}_{4}$ nanocrystals and its coupling with peroxymonosulfate for degradation of bisphenol A. Chem. Eng. J. 353, 329-339.

Yao, B., Li, R., Yan, S., Chan, S.-A., Song, W., 2018. Occurrence and estrogenic activity of steroid hormones in Chinese streams: a nationwide study based on a combination of chemical and biological tools. Environ. Int. 118, 1-8.

Zhang, A., Jia, A., Park, M., Li, Y., Snyder, S.A., 2019. Genotoxicity assay and potential byproduct identification during different UV-based water treatment processes. Chemosphere 217, 176-182.

Zhang, J., Liu, S.-S., Yu, Z.-Y., Liu, H.-L., 2012. Significant contributions of ionic liquids containing tetrafluoroborate and trifluoromethanesulfonate to antagonisms and synergisms in multi-component mixtures. J. Hazard Mater. 209-210 (0), $158-163$.

Zhang, Q., Ma, X., Dzakpasu, M., Wang, X.C., 2017. Evaluation of ecotoxicological effects of benzophenone UV filters: luminescent bacteria toxicity, genotoxicity and hormonal activity. Ecotoxicol. Environ. Saf. 142, 338-347.

Zheng, K., Ma, X.Y., Hao, L.W., Wang, X.C., Jin, P.K., Yang, W.B., 2019. The establishment of algal toxicity detection method based on chlorophyll fluorescence imaging and its application in environmental monitoring. Acta Sci. Circumstantiae 39 (3), 768-773. 